Original Article

\title{
Does the $Q-H$ index show a stronger relationship than the $H: Q$ ratio in regard to knee pain during daily activities in patients with knee osteoarthritis?
}

\author{
Remi Fujita, PT $^{1,2)^{*}}$, Yasumoto Matsui, MD, PhD $^{2)}$, Atsushi Harada, MD, PhD ${ }^{2)}$, \\ Marie Takemura, MD, $\mathrm{PhD}^{2)}$, Izumi Kondo, $\mathrm{MD}, \mathrm{PhD}^{3)}$, Tetsuya Nemoto, $\mathrm{PhD}^{4}$, \\ Tadahiro Sakai, MD, PhD ${ }^{5)}$, Hideki Hiraiwa, MD, PhD ${ }^{5)}$, Susumu Ota, PT, $\mathrm{PhD}^{1)}$ \\ 1) Department of Rehabilitation and Care, Seijoh University: 2-172 Fukinodai, Tokai City, \\ Aichi 476-8588, Japan \\ 2) Department of Advanced Medicine, National Center for Geriatrics and Gerontology, Japan \\ 3) Department of Rehabilitation Medicine, National Center for Geriatrics and Gerontology, Japan \\ 4) Department of Gerontechnology, National Center for Geriatrics and Gerontology, Japan \\ 5) Department of Orthopaedic Surgery, Nagoya University Graduate School of Medicine, Japan
}

\begin{abstract}
Purpose] The purpose of this study was to elucidate the relationship between knee muscle strength and knee pain in activities of daily living, based on consideration of the difference between extension and flexion strength $(\mathrm{Q}-\mathrm{H})$ and the hamstring:quadriceps $(\mathrm{H}: \mathrm{Q})$ ratio in patients with knee osteoarthritis. [Subjects and Methods] The participants were 78 females with knee osteoarthritis, and a total of 133 knees that had not been treated surgically were the targets of this research. The legs were divided according to dominance. Isometric knee extension and flexion muscle strength and knee pain during activities of daily living were measured. The H:Q ratio (flexion/extension muscle strength) and the difference between extension and flexion strength, (extension muscle strength/weight) minus (flexion muscle strength/weight), that is, $\mathrm{Q}-\mathrm{H}$, were calculated. The correlation between these indices and the knee pain score during activities of daily living was investigated. [Results] Greater knee pain during activities of daily living was related to lower knee extension muscle strength and $\mathrm{Q}-\mathrm{H}$ in both the dominant and nondominant legs. Knee flexion muscle strength and the H:Q ratio were not significantly correlated with knee pain during any activities of daily living. [Conclusion] Knee extension muscle strength and $\mathrm{Q}-\mathrm{H}$ were found to be significantly correlated with knee pain during activities of daily living, whereas the H:Q ratio was not.

Key words: Knee extension and flexion muscle strength, Q - H, Knee pain
\end{abstract}

(This article was submitted Jul. 12, 2016, and was accepted Aug. 2, 2016)

\section{INTRODUCTION}

Knee osteoarthritis (OA) is a motor disorder that leads to decreased quality of life (QOL) ${ }^{1)}$ and physical function ${ }^{2,3)}$ in old age due to knee pain and is one of the causes of the need for nursing care. The prevention of knee OA and amelioration of its symptoms are urgent issues today due to rapidly increasing elderly populations. The importance of knee muscle strength training in conservative treatment is well known, and its effects have been verified in previous studies ${ }^{4-13)}$. These studies have demonstrated that one of its effects is to reduce pain. The pain of OA is often worsened with activity, and as OA progresses, pain may become more persistent and can also appear at rest and during the night ${ }^{14}$. In the abovementioned studies, however, pain assessment was performed only at rest or while walking and ascending/descending stairs.

In addition, the abovementioned studies have shown improvements in knee extension muscle strength after training, as

*Corresponding author. Remi Fujita (E-mail: fujita-r@seijoh-u.ac.jp)

(C2016 The Society of Physical Therapy Science. Published by IPEC Inc.

This is an open-access article distributed under the terms of the Creative Commons Attribution Non-Commercial No Derivatives (by-nc-nd) License $<$ http://creativecommons.org/licenses/by-nc-nd/4.0/>. 
well as reductions in pain in people with knee OA. The quadriceps are the largest group of muscles crossing the knee joint and the primary stabilizer of the knee and have the greatest potential to generate and absorb forces at the knee ${ }^{15)}$. Dynamic stability at the knee joint is provided by the muscles that surround the knee joint, the principal of which are the quadriceps and hamstring muscles ${ }^{16)}$. Self-reported knee instability has been linked to higher pain levels ${ }^{17)}$. Knee extension and flexion muscle strength are both lost as symptomatic knee OA progresses ${ }^{18,19)}$.

Evaluation of both quadriceps and hamstring muscle strength is therefore important, and the relationship of quadriceps and hamstring muscle strength with pain symptoms should be examined. The strength relationship between the quadriceps and hamstring muscles has been measured and reported by various researchers ${ }^{20-22}$. The ratio of quadriceps to hamstring muscle strength, usually assessed by the hamstring:quadriceps (H:Q) ratio, is important for the stability of the knee and for the balance of muscle strength ${ }^{20,23}$. On the other hand, Gibbon et al. argued that if discrimination is performed by comparing absolute differences, then equal absolute differences might be expected to result in equal discrimination of performance. Conversely, if choices are made based on a ratio comparison, then discrimination performance might be expected to be constant at constant ratios of a short to a long interval when the time values, short and long, are changed, but kept in the same ratio $^{24)}$. One may assume that both knee extension and flexion muscle strength would be lower with increasing knee pain, in which case there would be no change in the H:Q ratio. For this reason, the absolute difference between extension strength and flexion strength $(\mathrm{Q}-\mathrm{H})$ may be a more reasonable indicator of knee pain. In addition, positive correlation between strength and body size is expected ${ }^{25,26)}$; thus it is necessary to calculate the muscle strength/body weight ratio.

However, to our knowledge, the relationship between quadriceps and hamstring muscle strength and pain during detailed activities of daily living (ADL) has not been reported from the point of view of Q - H compared with the H:Q ratio.

To elucidate the relationship between muscle strength and pain symptoms, we investigated the relationship between knee pain in ADL and not only knee extension and flexion muscle strength but also Q - H and the H:Q ratio. As a supplement, $\mathrm{Q}-\mathrm{H}$ was divided by weight.

\section{SUBJECTS AND METHODS}

The participants of the present study were recruited from among female outpatients and inpatients diagnosed with knee OA, which had been treated in the orthopedics department of the National Center for Geriatrics and Gerontology in Obu City, Aichi Prefecture, Japan. The period of recruitment was from February 24, 2011, to May 31, 2013. The inclusion criterion was no severe cognitive impairment. Participants were excluded if they reported a previous knee joint replacement, hip or lumbar spine arthritis or other joint pathology causing lower-limb pain, or knee surgery. After selection, the participants were informed about the objectives of the study, and all participants signed a consent form to participate in this study.

The participants of this study were 78 females (mean age $73.6 \pm 8.4$ years), and a total of 133 knees that had not been treated surgically were the targets of this research. One of an individual's legs is generally dominant, and the other is nondominant. The leg with which the relatively skilled action of kicking a ball is done is generally the dominant leg, while the leg with which weight is supported is generally the nondominant $\operatorname{leg}^{27}{ }^{28)}$. Therefore, the legs were divided according to lower limb dominance, and the dominant leg was found to be the right leg in 72 females and the left leg in 6 females.

Knee extension and flexion muscle strength was measured using a prototype instrument developed jointly with the Department of Gerontechnology at our center. The instrument can be transported on a cart and uses a force gauge (ZP-500N, Imada Co., Ltd., Toyohashi, Aichi, Japan) to measure the precision of industrial products. In the pilot study, six healthy participants were randomly selected, and their left and right legs ( $\mathrm{n}=3$ for each) were measured. The intra-rater reliability was good for both knee extension (intraclass correlation coefficient $\left.\left(\mathrm{ICC}_{1,2}\right)=0.988\right)$ and flexion $\left(\mathrm{ICC}_{1,2}=0.951\right)$ muscle strength. Significant correlations were seen between measurements from the prototype instrument and an isokinetic dynamometer (Kin Com $500 \mathrm{H}$, Isokinetic International, Chattanooga, TN, USA). With subjects in a sitting position with their legs flexed $90^{\circ}$ and a strap on the ankle joint, knee extension and flexion muscle strength were measured isometrically for 3 seconds. Knee extension and flexion muscle strength were measured two times each in the left and right legs, and the better value for each side was utilized. Knee extension and flexion muscle strength were expressed as the proportion to body weight, the H:Q ratio (flexion strength/extension strength). The difference between extension and flexion strength, (extension strength/weight) minus (flexion strength/weight), that is, $\mathrm{Q}-\mathrm{H}$, was also calculated.

Knee pain during ADL in the dominant and nondominant legs was surveyed with a questionnaire. The ADL questionnaire used the Western Ontario and McMaster Universities Osteoarthritis Index (WOMAC) as a reference. The ADL questionnaire added the Japanese traditional style to 4 activities in the WOMAC and level ground walking. Stair climbing, lying down, standing up, and sitting on the floor with the legs folded underneath the body were assessed. The scale consisted of 5 grades, from 1 to 5 , with 1 corresponding to no pain and 5 corresponding to severe pain. The scores for each ADL measure and the total score obtained by summing the individual scores were used.

The correlation between the indices related to muscle strength and knee pain score during ADL was investigated using Pearson's correlation coefficient in the dominant and nondominant legs. IBM SPSS Statistics (Ver. 19.0, IBM Corp., Armonk, NY, USA) was used in all analyses. Statistical significance was established at $\mathrm{p}<0.05$.

The study was a case-control study, and ethical approval was obtained from the National Center for Geriatrics and Gerontology Research Ethics Committee. 
Table 1. Characteristics of the study participants

\begin{tabular}{lcc}
\hline & Dominant & Nondominant \\
\hline Knee extension muscle strength $(\mathrm{kg})$ & $18.9 \pm 5.69$ & $17.7 \pm 5.56$ \\
Knee extension strength/weight & $0.34 \pm 0.11$ & $0.32 \pm 0.10$ \\
Knee flexion muscle strength $(\mathrm{kg})$ & $8.50 \pm 3.33$ & $7.66 \pm 3.31$ \\
Knee flexion strength/weight & $0.16 \pm 0.06$ & $0.14 \pm 0.06$ \\
H:Q ratio & $0.46 \pm 0.14$ & $0.44 \pm 0.15$ \\
Q - H & $0.18 \pm 0.08$ & $0.18 \pm 0.08$ \\
Knee pain during activities of daily living & & \\
Level ground walking & $1.97 \pm 1.00$ & $2.04 \pm 1.06$ \\
Stair climbing & $2.48 \pm 1.18$ & $2.67 \pm 1.35$ \\
Lying down & $1.76 \pm 0.91$ & $1.71 \pm 0.80$ \\
Standing up & $2.11 \pm 0.97$ & $2.04 \pm 1.00$ \\
Sitting on the floor with the legs folded underneath the body & $3.75 \pm 1.66$ & $3.70 \pm 1.72$ \\
Total & $12.1 \pm 4.68$ & $12.2 \pm 4.93$ \\
\hline Mean \pm SD & &
\end{tabular}

Table 2. Correlation between knee muscle strength and knee pain during ADL in the dominant leg

\begin{tabular}{lcccccc}
\hline & \multicolumn{5}{c}{ ADL } \\
& $\begin{array}{c}\text { Level ground } \\
\text { walking }\end{array}$ & $\begin{array}{c}\text { Stair } \\
\text { climbing }\end{array}$ & $\begin{array}{c}\text { Lying } \\
\text { down }\end{array}$ & $\begin{array}{c}\text { Standing } \\
\text { up }\end{array}$ & $\begin{array}{c}\text { Sitting on the floor with the legs } \\
\text { folded underneath the body }\end{array}$ & Total \\
\hline Extension muscle strength & $-0.34^{* *}$ & $-0.28^{*}$ & -0.17 & -0.13 & -0.19 & $-0.27^{*}$ \\
Extension strength/weight & $-0.36^{* *}$ & $-0.34^{* *}$ & -0.23 & -0.19 & -0.18 & $-0.31^{*}$ \\
Flexion muscle strength & -0.22 & -0.16 & 0.01 & -0.05 & -0.12 & -0.14 \\
Flexion strength/weight & -0.23 & -0.15 & -0.05 & -0.05 & -0.08 & -0.14 \\
H:Q ratio & 0.04 & 0.11 & 0.09 & 0.05 & -0.004 & 0.06 \\
Q - H & $-0.29^{*}$ & $-0.32^{*}$ & $-0.27^{*}$ & -0.20 & -0.17 & $-0.29^{*}$ \\
\hline
\end{tabular}

H:Q ratio: hamstring:quadriceps ratio; $\mathrm{Q}-\mathrm{H}$ : the difference between extension strength and flexion strength. *Significance of $\mathrm{p}<0.05$,

**Significance of $\mathrm{p}<0.01$ (Pearson's correlation coefficient)

\section{RESULTS}

Demographic data of participants are listed in Table 1.

In the dominant leg, significant correlations were seen between knee extension muscle strength and knee pain scores during level ground walking $(r=-0.34, \mathrm{p}=0.006)$ and stair climbing $(\mathrm{r}=-0.28, \mathrm{p}=0.029)$ and between knee extension strength and the total score $(\mathrm{r}=-0.27, \mathrm{p}=0.033)$. The correlation between knee extension strength/weight and knee pain scores was also significant (walking, $r=-0.36, p=0.004$; stair climbing, $r=-0.34, p=0.007$; total pain score, $r=-0.31$, $p=0.014$ ) (Table 2).

In the nondominant leg, significant correlations were seen between knee extension muscle strength and knee pain scores during level ground walking $(\mathrm{r}=-0.33, \mathrm{p}=0.005)$, stair climbing $(\mathrm{r}=-0.25, \mathrm{p}=0.034)$, sitting on the floor with the legs underneath the body $(\mathrm{r}=-0.33, \mathrm{p}=0.005)$, and the total score $(\mathrm{r}=-0.31, \mathrm{p}=0.009)$. Regarding knee extension strength/weight, knee pain scores during standing up were added to the significant correlations (Table 3 ).

Knee flexion muscle strength was not found to be significantly correlated with knee pain in any activity except sitting on the floor with the legs underneath the body, which showed significant correlation in the nondominant leg (Tables 2 and 3 ).

The H:Q ratio was not significantly correlated with knee pain during any ADL, irrespective of dominancy.

On the other hand, the correlation with the knee pain score and $\mathrm{Q}-\mathrm{H}$ were significant in all activities except standing up and sitting on the floor with the legs underneath the body in the dominant leg. In the nondominant leg, the correlations with the knee pain score and $\mathrm{Q}-\mathrm{H}$ were significant during all activities except lying down (Tables 2 and 3 ).

\section{DISCUSSION}

In the present study, we investigated the relationship between knee extension and flexion muscle strength and knee pain in ADL in the dominant and nondominant leg. The tendency for significant correlations between knee pain scores was basically similar, irrespective of dominancy. In both the dominant and nondominant legs, there were moderate but significant correlations between knee pain and the absolute value of knee extension muscle strength, the extension strength/weight ratio, and 
Table 3. Correlation between knee muscle strength and knee pain during ADL in the nondominant leg

\begin{tabular}{lcccccc}
\hline & \multicolumn{5}{c}{ ADL } \\
\hline & $\begin{array}{c}\text { Level ground } \\
\text { walking }\end{array}$ & $\begin{array}{c}\text { Stair } \\
\text { climbing }\end{array}$ & $\begin{array}{c}\text { Lying } \\
\text { down }\end{array}$ & $\begin{array}{c}\text { Standing } \\
\text { up }\end{array}$ & $\begin{array}{c}\text { Sitting on the floor with the legs } \\
\text { folded underneath the body }\end{array}$ & Total \\
\hline Extension muscle strength & $-0.33^{* *}$ & $-0.25^{*}$ & -0.09 & -0.19 & $-0.33^{* *}$ & $-0.31^{* *}$ \\
Extension strength/weight & $-0.33^{* *}$ & $-0.32^{* *}$ & -0.10 & $-0.31^{*}$ & $-0.32^{* *}$ & $-0.35^{* *}$ \\
Flexion muscle strength & -0.20 & -0.22 & -0.05 & -0.08 & $-0.27^{*}$ & -0.22 \\
Flexion strength/weight & -0.18 & -0.23 & -0.06 & -0.11 & -0.21 & -0.21 \\
H:Q ratio & 0.10 & -0.02 & -0.04 & 0.16 & 0.04 & 0.06 \\
Q - H & $-0.30^{*}$ & $-0.24^{*}$ & -0.09 & $-0.33^{* *}$ & $-0.27^{*}$ & $-0.31^{*}$ \\
\hline
\end{tabular}

$\mathrm{H}: \mathrm{Q}$ ratio: hamstring:quadriceps ratio; $\mathrm{Q}-\mathrm{H}$ : the difference between extension strength and flexion strength. *Significance of $\mathrm{p}<0.05$, **Significance of $\mathrm{p}<0.01$ (Pearson's correlation coefficient)

Q - H. Knee flexion muscle strength and the H:Q ratio were not significantly correlated with knee pain during any activity.

In past reports on the relationship between muscle strength and knee pain, the knee-specific VAS pain score and the association between tertiles of quadriceps strength (expressed as quadriceps strength relative to body weight $(\mathrm{Nm} / \mathrm{kg})$ ) were examined. In a study with 265 males and females with symptomatic knee OA, subjects with greater quadriceps strength had less knee pain ${ }^{29}$. In another report, the association of the consistency of frequent knee pain (FKnP) with extension muscle strength $(\mathrm{Nm})$ was also evaluated. In a study of 2,940 participants either with or at high risk of knee OA, knees with consistent pain had the lowest quadriceps strength, while those with inconsistent pain had intermediate quadriceps strength; those with no $\mathrm{FKnP}$ had the greatest quadriceps strength ${ }^{30}$. In addition, whether maximal isometric extension and flexion muscle strength $(\mathrm{N})$ differ between OA knees with frequent pain (most days of the month within the past 12 months) and contralateral knees without pain was examined. Painful knees showed lower maximal extension muscle strength than contralateral knees without pain, and there were no significant differences in flexion muscle strength in 17 males and 31 females with knee $\mathrm{OA}^{31}$. Similar to these previous studies, both the absolute value of extension muscle strength and the extension strength/weight ratio in this study were related to knee pain in both legs, but knee flexion muscle strength was not found to be correlated with knee pain.

Self-reported knee instability has been linked to higher pain levels ${ }^{17}$. Because the lower limb musculature is the natural brace of the knee joint, important muscle dysfunction may arise from either quadriceps weakness or weakness of the hamstring relative to the quadriceps, which is usually assessed by the $\mathrm{H}: \mathrm{Q}$ ratio ${ }^{32-34)}$. In the present study, however, we found that the H:Q ratio was not significantly correlated with knee pain during any ADL. The reason for this, we supposed, is that both knee extension and flexion muscle strength may decrease with increasing knee pain, in which case there would be no change in the H:Q ratio. In a previous examination of whether the H:Q ratio predicts risk for incident symptomatic whole knee OA in adults aged 50-79 years, the H:Q ratio was not found to be predictive of incident symptomatic whole knee OA in either gender. In other reports, the correlation of the $\mathrm{H}: \mathrm{Q}$ ratio with the usual level of pain was negative in patients with knee $\mathrm{OA}^{20)}$, and pain intensity during testing did not affect the $\mathrm{H}: \mathrm{Q}$ ratio in subjects with knee $\mathrm{OA}^{19)}$. The results of this study agree with these previous reports. This study also found that $\mathrm{Q}-\mathrm{H}$ was significantly correlated with knee pain during many activities. Therefore, it may be that $\mathrm{Q}-\mathrm{H}$ is a more reasonable indicator than the $\mathrm{H}: \mathrm{Q}$ ratio, as $\mathrm{Q}-\mathrm{H}$ may better reflect the balance of muscle strength, that is, the stability of the knee, than the H:Q ratio. Additionally, the results regarding the correlation between $\mathrm{Q}-\mathrm{H}$ and knee pain showed no difference between the dominant and nondominant legs.

Limitations of this study include that it was a cross-sectional study, and therefore comments about causality cannot be made. Second, we did not account for other individual characteristics affecting knee pain, such as knee alignment and inflammation.

In conclusion, knee extension muscle strength and the difference between extension strength/weight and flexion strength/ weight were found to be significantly correlated with knee pain during ADL, whereas the hamstring:quadriceps ratio was not. This finding suggests that increasing the strength of knee extensors while maintaining a balance with hamstring muscle strength may contribute to reducing knee pain during ADL.

\section{ACKNOWLEDGEMENT}

The authors gratefully acknowledge the contributions of the study participants in the orthopedics department of the National Center for Geriatrics and Gerontology, Japan. 


\section{REFERENCES}

1) Rejeski WJ, Shumaker S: Knee osteoarthritis and health-related quality of life. Med Sci Sports Exerc, 1994, 26: 1441-1445. [Medline] [CrossRef]

2) Dekker J, van Dijk GM, Veenhof C: Risk factors for functional decline in osteoarthritis of the hip or knee. Curr Opin Rheumatol, 2009, 21: 520-524. [Medline] [CrossRef]

3) Sharma L, Cahue S, Song J, et al.: Physical functioning over three years in knee osteoarthritis: role of psychosocial, local mechanical, and neuromuscular factors. Arthritis Rheum, 2003, 48: 3359-3370. [Medline] [CrossRef]

4) Topp R, Woolley S, Hornyak J 3rd, et al.: The effect of dynamic versus isometric resistance training on pain and functioning among adults with osteoarthritis of the knee. Arch Phys Med Rehabil, 2002, 83: 1187-1195. [Medline] [CrossRef]

5) Thomas KS, Muir KR, Doherty M, et al.: Home based exercise programme for knee pain and knee osteoarthritis: randomised controlled trial. BMJ, 2002, 325: 752. [Medline] [CrossRef]

6) O'Reilly SC, Muir KR, Doherty M: Effectiveness of home exercise on pain and disability from osteoarthritis of the knee: a randomised controlled trial. Ann Rheum Dis, 1999, 58: 15-19. [Medline] [CrossRef]

7) van Baar ME, Dekker J, Oostendorp RA, et al.: The effectiveness of exercise therapy in patients with osteoarthritis of the hip or knee: a randomized clinical trial. J Rheumatol, 1998, 25: 2432-2439. [Medline]

8) Quilty B, Tucker M, Campbell R, et al.: Physiotherapy, including quadriceps exercises and patellar taping, for knee osteoarthritis with predominant patellofemoral joint involvement: randomized controlled trial. J Rheumatol, 2003, 30: 1311-1317. [Medline]

9) Petrella RJ, Bartha C: Home based exercise therapy for older patients with knee osteoarthritis: a randomized clinical trial. J Rheumatol, 2000, 27: 2215-2221. [Medline]

10) Hopman-Rock M, Westhoff MH: The effects of a health educational and exercise program for older adults with osteoarthritis for the hip or knee. J Rheumatol, 2000, 27: 1947-1954. [Medline]

11) Fransen M, Crosbie J, Edmonds J: Physical therapy is effective for patients with osteoarthritis of the knee: a randomized controlled clinical trial. J Rheumatol, 2001, 28: 156-164. [Medline]

12) Baker KR, Nelson ME, Felson DT, et al.: The efficacy of home based progressive strength training in older adults with knee osteoarthritis: a randomized controlled trial. J Rheumatol, 2001, 28: 1655-1665. [Medline]

13) Ettinger WH Jr, Burns R, Messier SP, et al.: A randomized trial comparing aerobic exercise and resistance exercise with a health education program in older adults with knee osteoarthritis. The Fitness Arthritis and Seniors Trial (FAST). JAMA, 1997, 277: 25-31. [Medline] [CrossRef]

14) Brandt KD, Doherty M, Lohmander LS: Osteoarthritis, 2nd ed. Oxford: Oxford University Press, 2003.

15) Losada CJ, Altman RD: Management of osteoarthritis. Arthritis and allied conditions, Koopman WJ (ed.), Baltimore: Williams \& Wilkins, 1996.

16) Jenkins DB: Hollinshead's functional anatomy of the limbs and back. Philadelphia, 1991.

17) Felson DT, Niu J, McClennan C, et al.: Knee buckling: prevalence, risk factors, and associated limitations in function. Ann Intern Med, 2007 , 147: 534-540. [Medline] [CrossRef]

18) Tan J, Balci N, Sepici V, et al.: Isokinetic and isometric strength in osteoarthrosis of the knee. A comparative study with healthy women. Am J Phys Med Rehabil, 1995, 74: 364-369. [Medline] [CrossRef]

19) Hall KD, Hayes KW, Falconer J: Differential strength decline in patients with osteoarthritis of the knee: revision of a hypothesis. Arthritis Care Res, 1993, 6: 89-96. [Medline] [CrossRef]

20) Hayes KW, Falconer J: Differential muscle strength decline in osteoarthritis of the knee. A developing hypothesis. Arthritis Care Res, 1992, 5: 24-28. [Medline] [CrossRef]

21) Holmes JR, Alderink GJ: Isokinetic strength characteristics of the quadriceps femoris and hamstring muscles in high school students. Phys Ther, 1984, 64: 914-918. [Medline]

22) Nosse LJ: Assessment of selected reports on the strength relationship of the knee musculature. J Orthop Sports Phys Ther, 1982, 4: 1. [Medline] [CrossRef]

23) Adegoke BO, Mordi EL, Akinpelu OA, et al.: Isotonic quadriceps-hamstring strength ratios of patients with knee osteoarthritis and apparently healthy controls. Afr J Biomed Res, 2007, 10: 211-216.

24) Gibbon J, Fairhurst S: Ratio versus difference comparators in choice. J Exp Anal Behav, 1994, 62: 409-434. [Medline] [CrossRef]

25) Maughan RJ, Watson JS, Weir J: Strength and cross-sectional area of human skeletal muscle. J Physiol, 1983, 338: 37-49. [Medline] [CrossRef]

26) Harris T: Muscle mass and strength: relation to function in population studies. J Nutr, 1997, 127: 1004S-1006S. [Medline]

27) Gabbard C, Hart S: A question of foot dominance. J Gen Psychol, 1996, 123: 289-296. [Medline] [CrossRef]

28) Peters M: Footedness: asymmetries in foot preference and skill and neuropsychological assessment of foot movement. Psychol Bull, 1988 , 103: 179-192. [Medline] [CrossRef]

29) Amin S, Baker K, Niu J, et al.: Quadriceps strength and the risk of cartilage loss and symptom progression in knee osteoarthritis. Arthritis Rheum, 2009, 60: 189-198. [Medline] [CrossRef]

30) Neogi T, Nevitt MC, Yang M, et al.: Consistency of knee pain: correlates and association with function. Osteoarthritis Cartilage, 2010, 18: 1250-1255. [Medline] [CrossRef]

31) Sattler M, Dannhauer T, Hudelmaier M, et al. OAI investigators: Side differences of thigh muscle cross-sectional areas and maximal isometric muscle force in bilateral knees with the same radiographic disease stage, but unilateral frequent pain-data from the osteoarthritis initiative. Osteoarthritis Cartilage, 2012, 20: 532-540. [Medline] [CrossRef]

32) Aagaard P, Simonsen EB, Trolle M, et al.: Isokinetic hamstring/quadriceps strength ratio: influence from joint angular velocity, gravity correction and contraction mode. Acta Physiol Scand, 1995, 154: 421-427. [Medline] [CrossRef]

33) Segal NA, Torner JC, Felson D, et al.: Effect of thigh strength on incident radiographic and symptomatic knee osteoarthritis in a longitudinal cohort. Arthritis Rheum, 2009, 61: 1210-1217. [Medline] [CrossRef]

34) Sharma L, Pai YC, Holtkamp K, et al.: Is knee joint proprioception worse in the arthritic knee versus the unaffected knee in unilateral knee osteoarthritis? Arthritis Rheum, 1997, 40: 1518-1525. [Medline] [CrossRef] 